\title{
Processes of Negotiating Identity in a Cross Sector Partnership
}

\author{
Easter, Sarah; Schultz, Majken
}

Document Version

Accepted author manuscript

Published in:

Proceedings of the Seventy-seven Annual Meeting of the Academy of Management

DOI:

10.5465/AMBPP.2017.95

Publication date:

2017

License

Unspecified

Citation for published version (APA):

Easter, S., \& Schultz, M. (2017). Processes of Negotiating Identity in a Cross Sector Partnership. In G. Atinc (Ed.), Proceedings of the Seventy-seven Annual Meeting of the Academy of Management [12572] Academy of Management. Academy of Management Proceedings https://doi.org/10.5465/AMBPP.2017.95

Link to publication in CBS Research Portal

\section{General rights}

Copyright and moral rights for the publications made accessible in the public portal are retained by the authors and/or other copyright owners and it is a condition of accessing publications that users recognise and abide by the legal requirements associated with these rights.

Take down policy

If you believe that this document breaches copyright please contact us (research.lib@cbs.dk) providing details, and we will remove access to the work immediately and investigate your claim. 


\title{
Processes of Negotiating Identity in a Cross Sector Partnership
}

\section{Sarah Easter and Majken Schultz}

Article in proceedings (Accepted manuscript)

CITE: Easter, S., \& Schultz, M. (2017). Processes of Negotiating Identity in a Cross Sector Partnership. In G. Atinc (Ed.), Proceedings of the Seventy-seven Annual Meeting of the Academy of Management[12572] Briar Cliff Manor, NY: Academy of Management. Academy of Management Proceedings, DOI: 10.5465/AMBPP.2017.95

\author{
DOI: 10.5465/AMBPP. 2017.95
}

Uploaded to Research@CBS: January २०19 


\title{
PROCESSES OF NEGOTIATING IDENTITY IN A CROSS SECTOR PARTNERSHIP: HOMELESSNESS THROUGH DIFFERENT LENSES
}

\author{
SARAH EASTER \\ College of Business Administration \\ Abilene Christian University \\ MAJKEN SCHULTZ \\ Copenhagen Business School
}

\begin{abstract}
In spite of the growing importance of cross sector partnerships to address societal challenges, the extant organizational studies literature has tended to hone in on identity in organizational fields, single organizations and teams. Recognizing this significant lacuna, we present an ethnographic, grounded theory study of the processes by which organizations involved in a cross sector partnership continuously negotiate the partnership's identity in attempts to tackle the issue of homelessness. Our findings highlight how the identity of a partnership involving actors from public, private and non-profit sectors is negotiated and re- negotiated and, in turn, the strategies that actors enact in order to influence what the partnership is in the process of becoming. Specifically, we capture how actors, who are representative of both the partnership and their own organizations and thus insider- outsiders, enact four core influencing resources - finances, research, on the ground experiences and communications - in their everyday interactions to continuously maintain, shape and alter the partnership's identity; we refer to these processes as "partnership identity-as-negotiation". We contribute to the emerging stream of literature on identity involving multiple organizations by explicating identity-work processes in cross sector partnerships characterized by the presence of multiple understandings of identity and ongoing interfaces with permeable boundaries.
\end{abstract}

\section{INTRODUCTION}

Cross sector partnerships - collaborative partnerships that cut across sectors - have surfaced as a viable organizing mechanism to tackle a myriad of complex challenges ${ }^{1}$ (Koschmann, Kuhn \& Pfaffer, 2012). Increasingly, in today's multi-faceted operating environment, organizations are realizing the significance of cooperating across sectors - public, private and nonprofit - in order to address grand challenges (Ferraro, Etzion \& Gehman, 2015) such as global poverty (Murphy, Perrot \& Rivera-Santos, 2012) and climate change (Jay, 2013). For the benefits that cross sector partnerships can offer, organizational arrangements that bring

\footnotetext{
${ }^{1}$ While a variety of terminology is used in the literature in regards to partnerships involving multiple sectors that focus on tackling societal challenges including, for example, cross sector partnership (Koschmann, et al., 2012), collaborative partnership (Maguire \& Hardy, 2005), social partnership (Waddock, 1991), social alliance (Berger, Cunningham \& Drumwright, 2004), intersectoral partnership (Waddell \& Brown, 1997), and issues management alliance (Austrom \& Lad, 1989), we take up the term cross sector partnership for consistency sake throughout.
} 
together actors from different perspectives, organizations and sectors can result in identity issues among actors. Specifically, actors must simultaneously juggle the needs of the partnership alongside those of the involved organizations in an ongoing manner, meaning that identity and identity tensions are likely to play a central role (Maguire \& Hardy, 2005). In this study, we focus on a cross sector partnership to end homelessness in Western Canada.

Research on identity has blossomed over the last three decades and addresses how identities develop, unfold and are altered over time based upon ongoing interactions among involved stakeholders (Schultz, Maguire, Langley \& Tsoukas, 2012). While the extant literature has tended to focus on identity change within single-organization contexts, increasingly scholars are examining organizational arrangements that involve multiple actors and transcend the boundaries of a single firm, particularly where it concerns mergers and acquisitions (e.g., Drori, Wrzesniewski \& Ellis, 2013). Within the context of mergers and acquisitions, the aim is to create a shared integrated identity between the organizations and associated actors coming together. In contrast, we know very little about the processes of identity change in cross sector partnerships, where more than two organizational boundaries conjoin even as each involved organization retains its own distinct identity. This lacuna is particularly significant given the growing importance of cross sector partnerships in society (e.g., Ferraro, Etzion \& Gehman, 2015) and the notion that they are arguably more complex in comparison to mergers and acquisitions. Without market or hierarchical forms of control, cooperation has to be negotiated continually by actors who are not only involved in the collaboration, but who also represent their respective organizations (Hardy, Lawrence \& Grant, 2005) and are thus insider-outsiders. Put differently, cross sector partnerships are characterized by ongoing permeable interfaces (e.g., Hardy, Lawrence \& Phillips, 2006; Lawrence, Hardy \& Phillips, 2002) and multiple understandings of identity (e.g., Le Ber \& Branzei, 2010; Murphy et al., 2012), where the partnership identity is likely to be continuously altered and shaped among involved actors over time. Yet, how these processes play out and the strategies that actors utilize to manage ongoing identity tensions in cross sector partnerships remains an unexplored, but promising territory, particularly beyond the individual level of analysis (see Maguire \& Hardy, 2005). Thus, we ask: by what processes and strategies do organizational actors involved in a cross sector partnership negotiate the partnership's identity over time? We use the term negotiation very intentionally as one of the possible means of "getting things accomplished" when actors must work together to get something done, which can involve overt strategies such as arguing or debating as well as covert tactics such as power brokering and gaining tacit understanding (Strauss, 1978:2).

\section{IDENTITY CHANGE IN CROSS SECTOR PARTNERSHIPS}

Process based view of identity. In this study, we take up the process based view of identity (e.g., Hatch \& Schultz, 2002; Gioia \& Patvardhan, 2012; Gioia et al., 2013). We draw on the emerging view (Gioia \& Pardvardhan, 2012; Gioia et al., 2010; Kreiner, Hollensbe, Sheep, Smith \& Kataria, 2015; Elstak et al., 2015; Ravasi \& Schultz, 2006; Schultz, 2016; Schultz et al., 2012; Schultz \& Hernes, 2013) that consideration needs to be given to both what constitutes continuity in identity alongside the actual processes of ongoing identity change in order to capture the organizational identity process in a holistic manner. We refer to identity as both the expressed identity claims and associated understandings or meanings (Ravasi \& Schultz, 2006), which develop, unfold and are altered over time based upon continuous interactions among all involved stakeholders (Schultz et al., 2012). 
Review of relevant literature. We chose to hone in on the processes of identity change in the promising, yet underexplored context of a cross sector partnership. In our literature review, we focus on the following dimensions: negotiation, organizational boundaries, perception of stakeholders, multiple understandings of identity and identity changes, which we review below.

To date, the incorporation of negotiation as a process in identity change has largely centered on those that are formalized and/or explicit in nature. For example, Gioia et al. (2010:23-24) conceptualize negotiation in terms of "discussion", "discourse", "debate" and "argument" in which case involved actors are actively engaged in vying for certain identity claims and associated understandings in an explicit and overt manner, such as actively considering identity claims and/or understandings in organized meetings. In taking up Strauss's (1978) notion of negotiation, we consider how identity negotiations play out holistically, including the incorporation of subtle and informal strategies, which has largely been unexplored.

In regards to organizational boundaries, processes of identity change are likely to be made more complex in the context of loosely structured organizational arrangements such as cross sector partnerships. The involved stakeholders function as insider-outsiders (Maguire \& Hardy, 2005) in comparison to contexts with more defined boundaries where stakeholders are externally or internally derived. There is a paucity of research that provides rich, contextualized accounts of identity work at the group level that captures the multitude of vantage points of involved stakeholders and their associated strategies utilized to form, alter, maintain and/or strengthen group-level identities (see Langley et al. as one exception).

What's more, processes of identity change are likely to be further complicated in the presence of multiple identity claims and/or understandings. Gioia and colleagues (Gioia et al., 2013) note that the literature as a whole remains relatively silent as it relates to multiple understandings of identity. This is surprising given that today's organizations are likely coping with environments and involved actors that support multiple conceptions of identity (e.g., Corley, 2004; Gioia et al., 2000). The notion of multiple identity claims and/or understandings of identity is particularly important when considering cross sector partnerships involving the coming together of players from different organizations and sectors with different visions, work practices and histories (e.g., Hardy et al., 2006; Le Ber \& Branzei, 2010; Murphy et al., 2012, 2014; Selsky \& Parker, 2005). While Maguire and Hardy (2005) suggest that identity conflicts are likely to play a central and visible role in cross sector partnerships and the authors examine identity work at the individual level of analysis, we lack studies that investigate how multiple identity claims and/or understandings actually play out in practice over time at the group level and beyond.

The literature that focuses on processes of identity construction and reconstruction, has tended to hone in on planned identity change in the context of major transformational shifts (e.g., Clark, Gioia, Ketchen, \& Thomas, 2010; Gioia et al., 2013; Ravasi \& Schultz, 2006; Hatch, Schultz \& Skov, 2015) that do not fully account for ongoing, continuous identity changes. In their survey of the organizational identity change literature, Gioia et al. (2013) note that little theoretical or empirical attention has been given to examining non-teleological changes (or identity changes that are not entirely planned), with some exceptions (e.g., Schultz \& Hernes, 2013). There is a paucity of research that focuses on the continuous and iterative processes of identity construction and reconstruction processes at the group level that result from the everyday interactions between involved actors. This is particularly important in the context of cross sector partnerships that are characterized by continuous organizational change (see, for example, Jay, 2013). 


\section{METHODOLOGY}

Overview. Given the lack of research emphasis concerning identity work in cross sector partnerships, we employed ethnographic (Cunliffe, 2010), grounded theory (Glaser \& Strauss, 1967) methodology. The first author carried out a sixteen-month longitudinal study of a coalition to end homelessness in Western Canada (referred to as Coalition), a cross sector partnership involving over forty players from the public, private and nonprofit sectors. We took up Moore's (2011) conception of holistic ethnography, which recognizes and incorporates the distinct groups and perspectives involved in developing an overall narrative of the phenomena being studied. This entailed an iterative process utilizing the key tenets of grounded theory constant comparative method, theoretical coding, theoretical sampling and theoretical sensitivity (O’Reilly, Paper \& Marz, 2012) - until theoretical saturation was achieved.

Data collection. Our principal means of data collection involved the first author conducting semi-structured interviews and carrying out participant observation. The interviews focused on each actor's perspectives of the Coalition and its inner workings given the variety of different participants involved. In total, 58 interviews were carried out with 47 informants. To provide a more holistic account of each interviewee interaction, the first author also generated field notes. In terms of nonparticipant observation, the first author sat in on as many Coalition meetings as possible including attending regular Management meetings and the Coalition's annual general meeting. In addition, we compiled a multitude of archival documents, including, but not limited to, Coalition annual reports dating back to 2008 and Coalition meeting notes dating back to 2007. In total, our data set included 2,500+ pages of documentation and over 300 documents.

Data analysis. In the earlier stages of analysis, we used an 'open coding' system (Glaser \& Strauss, 1967), which attempted to adhere closely to the terms used by informants. Once we were able to articulate some of the initially surfaced themes, the first author set up meetings with Coalition staff to review these nascent ideas, clarify issues/ideas that emerged and to obtain their thoughts as to our early sensemaking. We sought out additional information, both through conducting additional interviews and consulting archival documentation, based upon ideas generated in discussion, that could substantiate or expound upon insights. As we began to notice patterns in the data, the open codes were combined into higher order themes, as relevant (Gioia et al., 2012), resulting in approximately 50 codes.

To facilitate formal coding, we imported materials into ATLAS/ti (Muhr, 1991; 1997). Utilizing Atlas/ti as a supporting analytical tool enabled us to code passages within documents and examine the frequency in which codes appeared in the data in order to begin to see additional patterns as well as to better ascertain the salience of themes. It also served as a mechanism for generating memos: "the theorizing write-up of ideas about codes and their relationships as they strike the analyst while coding" (Glaser, 1978:83), to help ensure theoretical sensitivity. We constructed an initial process model focused on the negotiation of multiple understandings of partnership identity. This emergent model was continually refined as we consulted the literature and collected additional data. While participants had some clarifications, in all cases, they agreed that the emergent sensemaking of the Coalition was reflective of their own experiences.

\section{FINDINGS}


Multiple understandings of partnership identity. The Coalition's articulated identity as a partnership involving organizational actors from multiple sectors coming together with the expressed purpose of ending homelessness in the region was rarely altered in the years since it was formed in 2008. Yet, we realized that there were a wide variety of different identity understandings about partnership, homelessness and ending homelessness. The various meanings ascribed to partnership, homelessness and ending homelessness tended to fall on a continuum ranging from narrow (i.e., concretely defined) to wide net (i.e., encompass multiple and holistic paths forward) viewpoints. For example, concerning the partnership dimension, some partners, particularly business and governmental actors, believed that a project based approach should be taken that involved actors on an as-needed basis (i.e., narrow viewpoint). Other partners, though, particularly many from the non-profit sector, believed that partnership should entail true collaboration and involve relevant actors in all aspects of the coalition (i.e., wide net approach). In regards to homelessness, some actors believed that an emphasis should be given to those with long-term or repeated episodes of homelessness (i.e., concretely defined) while others felt that a wide net approach needed to be taken that addressed the many faces that homelessness can take.

Insider-outsider roles with permeable boundaries. In discussing their underlying understandings of the Coalition's identity, organizational actors frequently referred to the identities of their respective organizations and/or stakeholder groups. Partners described the challenges associated with their insider-outsider roles, balancing the goals of their respective organizations and/or stakeholder groups alongside those of the Coalition.

Latent nature of identity understandings. In spite of the presence of multiple identity understandings, further complicated by the Coalition's permeable boundaries, individuals' different interpretations were rarely openly discussed. Rather priority areas or manifestations of identity, linked to, by and large, tacit understandings of the Coalition's identity, were considered at the Coalition table, such as participants deliberating the initiatives and projects that the Coalition should put its energy and resources toward.

Formalized and planned negotiations. The formal strategies that the Coalition enacted mainly centered upon a regular planning process in an effort to mobilize the various partners involved around a shared identity. The formalized planning process was facilitated by the leadership team, specifically the Executive Director. We discovered that the ways in which each Executive Director enacted identity, particularly where it concerns the partnership dimension, shifted over time. The partnership dimension of the Coalition's identity shifted from a wide net (e.g., collaborative) approach under the First and Second Executive Director to a narrow (e.g., project based) viewpoint under the Third Director's tenure, even as a multitude of different identity understandings continued to exist.

Resources mobilized to influence identity. Involved partners utilized a variety of resources in their efforts to realize their own understandings of the Coalition's identity. This was particularly so as it relates to the homelessness and ending homelessness dimensions of identity. While resources were often enacted during planning processes, partners also utilized them in everyday interactions after strategic priorities for a given timeframe were finalized. Four core resources - research, finances, "on the ground" experiences and communications - were the most salient in the data. At the same time that the Coalition formally strove to negotiate a shared identity over time via formalized processes, partners continuously utilized four key resources in efforts to shape and alter the Coalition's identity in their desired direction, resulting in a fragmented identity 
Preview of the model. Our process model, which emerged from this study captures how partnership identity is continuously negotiated by insider-outsider players in settings characterized by the presence of multiple understandings of identity and ongoing interfaces with permeable boundaries. At its core, our model, which we coin 'partnership identity as negotiation', elucidates how insider-outsider actors enact a variety of strategies in their everyday interactions to maintain, shape, and/or alter the partnership's identity, resulting in ongoing identity changes.

The process begins with partners who come together as a part of the cross sector partnership. The involved partners serve as insider-outsiders in that they are partnership participants at the same time that they are representing their own organizations and associations, situated within the public, private or nonprofit sectors (outsiders). The result of a variety of insider-outsiders involved is multiple understandings of identity that actors bring with them into the partnership, which are largely latent in nature.

As a part of everyday interactions to maintain, shape and/or alter the partnership's identity, actors utilize a number of key strategies. The main formalized strategy of the partnership, carried out by the leadership team (e.g., in this case the Executive Director in consultation with the executive leadership team) is the formal planning process, which primarily influences how the involved actors are able to negotiate their different understandings of identity. At the same time, though, as authority in a cross sector partnership such as the Coalition is usually distributed and as senior leadership is responsible to and reports to the involved stakeholders, formalized strategies used to focus and direct the partnership only carry so much weight. Involved partners utilize a variety of resources, dependent on those at their disposal, such as funding, research, "on the ground" experiences in the field and media communications to iteratively shape the direction of the partnership, particularly as it relates to the focal societal issue at hand, in this case homelessness. While the formal planning process, facilitated and largely influenced by the Executive Director, seeks to serve as a stabilizing mechanism in order to help focus the partnership's identity at a given point in time, the ongoing informal conversations and the variety of influencing resources utilized by actors serve to continuously alter and shape the partnership identity and manifestations of identity. Thus, the identity-asnegotiation process is dynamic and iterative, involving ongoing identity changes.

\section{DISCUSSION AND CONCLUSION}

Our study focuses on a cross sector partnership setting, characterized by ongoing interfaces with permeable boundaries. In such multi-faceted contexts, involved actors function as insider-outsiders and authority to influence the identity of the interorganizational arrangement is likely to be much more distributed, leading to instances where the partnership identity is fragmented and continually negotiated. By elucidating the ongoing identity changes within the Coalition context, we add to the paucity of literature examining identity changes that are nonteleological in nature (see Gioia et al., 2013).

This study provides an empirical investigation as to how identity is negotiated over time in the presence of multiple understandings of identity. This is significant as scholars note (e.g., Corley, 2004; Gioia et al., 2000) that today's complex organizations are likely dealing with environmental settings and involved players that support multiple conceptions of organizational identity, even as the literature has remained fairly silent in this regard (Gioia et al., 2013). In capturing the multiple identity understandings at play, we discovered that they were largely 
latent in nature, which challenges Maguire and Hardy's (2005) finding that identity challenges in cross sector partnerships are likely to play a visible role. Further, by actively incorporating Strauss' (1978:2) notion of negotiation, we were able to more fully account for the various attempts to influence identity construction taking place within the Coalition, involving both formal and informal, subtle and overt strategies.

Finally, by focusing on identity change in a cross sector partnership setting, we extend the emerging literature on identity involving multiple organizations by highlighting the importance of identity even in loosely coupled organizational arrangements with permeable boundaries. Specifically, we illuminate how the variety of organizational actors involved in a cross sector partnership seek to continually influence the future direction of the Coalition, via their multiple identity understandings. This finding emphasizes the importance of continually revisiting who the partnership is in the process of becoming in order to chart a collective path forward. More research concerning the role of identity in such loosely structured organizational arrangements is needed. While we focused on a cross sector partnership context, specifically, this type of empirical investigation would be highly relevant and valuable in other types of settings with permeable boundaries and multiple conceptions of identity such as multinationals involving headquarter-subsidiary networks.

\section{REFERENCES AVAILABLE FROM AUTHORS}

